\title{
Protective Effect of Indole 3 Carbinol on Toxicity of Prenatal Exposure of Bisphenol A on Adult Rat Prostate" A Light and Electron Microscopic Study"
}

\author{
Saadia A. Shalaby, Essam M. Eid, Omar A. Allam, Naglaa A. Sarg, Maged A. Behery
}

\begin{abstract}
Department of Anatomy \& Embryology, Benha faculty of medicine, Banha University, Egypt.
\end{abstract}

Correspondence to: Maged

A. Behery, Department of Anatomy \& Embryology, Benha faculty of medicine, Banha University, Egypt.

Email:

maged.behery@fmed.bu.edu.eg

Received: 8 September 2019

Accepted: 17 May 2021

\begin{abstract}
Background: Bisphenol A (BPA) is a synthetic estrogen that predisposes to prostate disease. Indole-3-carbinol (I $3 \mathrm{C}$ ), found in vegetables, has chemo-protective properties in hormone dependent cells. This work investigates the harmful effect of prenatal exposure to BPA on rat prostate and the protective effect of I3C. Material\& methods: 30 pregnant albino rats were divided equally into 3 groups: 1- Control group: received no medication. 2- Bisphenol group: received $25 \mu \mathrm{g}$ BPA / kg body weight (BW), orally by gavage once daily from $8^{\text {th }}$ day of pregnancy to day 21 . 3Bisphenol and indole group: received $25 \mu \mathrm{g}$ BPA / $\mathrm{kg}$ BW, orally by gavage once daily plus $2 \mathrm{~g} \mathrm{I} 3 \mathrm{C} / \mathrm{kg}$ chow, from $8^{\text {th }}$ day of pregnancy to day 21. The prostates were collected from male offspring at 1 and 3 months after birth and were examined by light and electron microscopes. Results: The prostates from bisphenol group showed epithelial hyperplasia, increased intraluminal papillary projections and inflammatory cells in the
\end{abstract} interstitial space. The acinar cells presented heterochromatic irregular nuclei, vacuolated mitochondria and degenerated microvilli. Multiple layers of fibroblasts accumulate outside the basement membrane. The prostates from bisphenol and indole group showed a nearly intact simple columnar epithelial lining of the acini with basal rounded nuclei, normal mitochondria and intact apical microvilli.Conclusion: Prenatal exposure to BPA has a harmful effect on prostate. Maternal I3C feeding during pregnancy has a protective effect against the gestational BPA harmful imprinting on the prostate.

Keywords: Bisphenol A - Prostate - Indole-3-carbinol 


\section{Introduction:}

BPA is a synthetic estrogen used in production of polycarbonate plastics, epoxy resins, dental sealants and thermal receipt paper [1]. Epoxy resins are used as coating materials for food cans and metal lids, whereas polycarbonate is used in manufacture of house hold appliances, food packaging materials, plastic bottles, baby bottles and many other products [2]. Incomplete polymerization of BPA leads to its leaching and subsequent human oral exposure, as evidenced by the detection of BPA in human urine, serum, maternal and fetal plasma, amniotic fluid, placenta, and adipose tissue [3-4]. Recent studies have indicated that humans are also exposed to BPA through inhalation as well as via absorption through the skin and mucosal membranes of mouth [5].

In rodents, BPA has been shown to traverse the placenta [6] and it is also present in fetal serum during pregnancy [7]. Previous studies suggest that perinatal exposure to BPA has profound effects on rodent hormone dependent tissues long after exposure elapsed [8-9]. In prostate, BPA changes normal prostate development and predisposes to prostate disease [10]. I3C is the main bioactive compound found in high concentrations in vegetables of the
Brassicaceae family, including broccoli, cauliflower, cabbage and Brussels sprouts. I3C has been investigated for its chemoprotective properties in prostate gland [11]. In hormone dependent cells, 13C suppressed responsiveness to estrogen and decreased the expression of estrogen receptor alpha (ERa) [12].

Aim of the work: The aim of this work is to investigate the harmful effect of prenatal exposure to BPA on rat prostate at ages of 1 and 3 months and the possible protective effect of I3C.

\section{Materials and methods}

\section{A) Materials:}

1- Animals: Forty adult female albino rats were used in this study, their weight ranged from 200-250 gm each. They were obtained from animal house, Faculty of Veterinary Medicine, Benha University and were kept in the experimental animal unit, faculty of medicine, Benha University. The rats were maintained under standard conditions in metal cages $\left(2\right.$ rats $/$ cage) at temperature $22 \pm 2^{\circ} \mathrm{C}$, humidity $55 \pm 20 \%$ and with 12 hours dark/light cycle. They were allowed to free access to water supplied from glass bottles and balanced chow prepared in the experimental 
animal breeding farm, Helwan, Cairo. All aspects of the research were compiled with the protocols approved by local ethical committee of Faculty of Medicine, Benha University.

After a 1-week acclimation period, each 2 Females were caged overnight with one adult male of proven fertility. The day that sperms were found in the vagina (detected by microscopically examined vaginal swap) was designated day 1 of pregnancy.

2- Drugs: Two drugs were used in this study:

Bisphenol A (BPA): In the form of white powder dissolved in canola oil. The chemical is from LOBA Chemie, Pvt. Ltd. 107, Wodehouse Road, Mumbai 400005 India. For preparation of a solution of BPA with concentration of $25 \mu \mathrm{g}$ of BPA/ml: $250 \mathrm{mg}$ of BPA was added to $100 \mathrm{ml}$ of canola oil. Each one $\mathrm{ml}$ of the formed solution contained 2.5 $\mathrm{mg}$ of BPA. Then one $\mathrm{ml}$ of this solution was added to $9 \mathrm{ml}$ of canola oil. Each one $\mathrm{ml}$ of the formed solution contained $250 \mu \mathrm{g}$ of BPA. Then one $\mathrm{ml}$ of this solution was added to 9 $\mathrm{ml}$ of canola oil. Each one $\mathrm{ml}$ of the formed solution contained $25 \mu \mathrm{g}$ of BPA.

Indole 3 carbinol (I 3 C): In the form of white powder. The chemical is from LOBA Chemie, Pvt. Ltd. 107, Wodehouse Road,
Mumbai 400005 India. The drug was added to diet in dose $2 \mathrm{~g} / \mathrm{kg}$ chow.

\section{B) Experimental design:}

Pregnancy was proved and timed in only 30 female rats. These rats were divided equally into three groups:

1- Control group: 10 rats did not receive any medication.

2- Bisphenol group: 10 rats received $1 \mathrm{ml} / \mathrm{kg}$ bw from the solution with concentration of $25 \mu \mathrm{g}$ of BPA $/ \mathrm{ml}$, orally by gavage once daily [13] from $8^{\text {th }}$ day of pregnancy up to day 21 .

3- BPA with I 3 C group: 10 rats received 1 $\mathrm{ml} / \mathrm{kg}$ bw from the solution with concentration of $25 \mu \mathrm{g}$ of $\mathrm{BPA} / \mathrm{ml}$, orally by gavage once daily plus $2 \mathrm{~g}$ of I $3 \mathrm{C} / \mathrm{kg}$ chow [13] from 8th day of pregnancy up to day 21. Pups were left with lactating mothers for 2 weeks then isolated. Then they were divided into 2 subgroups to be sacrificed at 1 and 3 months after birth.

\section{1- Collection of prostate specimens:}

The rats of each group were anaesthetized by light ether inhalation, then each rat was placed on its back on polystyrene foam wrapped in foil, and the four limbs were spread. The four limbs were pinned firmly using 16 to 20 gauge needles. A V-shaped abdominal incision with 
its apex at the symphysis pubis was made through all layers. The lower abdominal viscera were thus widely exposed. The urinary bladder and ventral lobes of the prostate were freed carefully by sharp dissection .The urinary bladder and seminal vesicles were reflected to one side to reveal the ventrolateral boundary of the lateral lobe. The bulky and easily dissected, ventral and dorsolateral lobes were collected.

\section{2- Preparation for Light microscopic examination: [14].}

The specimens were fixed in $10 \%$ buffered neutral formalin then, transferred to ethyl alcohol for dehydration. The specimens were cleared in xylol. Then, impregnated with soft paraffin and finally, embedded in hard paraffin. Serial sections 5-7 pm thick were sliced and stained with Hematoxylin \& Eosin (H\&E) and Masson's Trichrome staining. The stained slices were photographed using a digital camera (Axioskop MRc5; Carl Zeiss, Oberkochen, Germany) attached to the microscope (Axioskop 40, Carl Zeiss, Germany) in Anatomy and Embryology Department, Benha faculty Of Medicine, Benha University

\section{3- Preparation for Electron microscopic examination: [14].}

The fresh specimens were fixed in $3 \%$ phosphate buffered glutaraldehyde. The specimens were post fixed in a freshly prepared $1 \%$ osmium tetroxide in phosphate buffer then dehydrated. The dehydration was completed by propylene. The specimens were then embedded in pre-labeled plastic capsule. These capsules were polymerized in a temperature controlled oven at $60^{\circ} \mathrm{C}$ for 48 hours. The polymerized block was trimmed into a pyramid with a small trapezoid surface. Semi thin sections were cut at 1 um thickness, and then the sections were stained with $1 \%$ toluidine blue stain and examined by the Olympus microscope for general orientation. Ultra-thin sections: $50 \mathrm{~nm}$ thick were obtained from the selected blocks and mounted on copper grids. After that the grids were stained with uranyl acetate followed by lead citrate and were examined by JEOL, JSM-52500 LV scanning electron microscope, Japan, at Electron Microscope Unit of Faculty of Medicine, Tanta University, Tanta, Egypt. Finally, the electron micrographs were taken from the selected areas. 


\section{Results:}

\section{A- Prostate gland of rats aged 1 month:}

\section{Light microscopy:}

1- Control group:

By H\&E stain, the acini were lined with simple columnar epithelium with basal dark rounded nuclei and supranuclear pale acidophilic cytoplasm. The acini were surrounded by a delicate layer of fibromuscular stroma. The interstitial space contained scanty connective tissue (fig. 1a,1b). By Masson's Trichrome stain, The interstitial space contained scanty collagen fibers (fig. 2).

\section{2- Bisphenol group:}

By $H \& E$ stain, some acini were lined with simple columnar epithelium but others had epithelial hyperplasia. The acini were surrounded by slightly thickened fibromuscular stroma. Some acini contained acidophilic secretions. The interstitial space contained increased amount of connective tissue, congested blood vessels and inflammatory cells (fig. 3a, 3b, 3c). By Masson's Trichrome stain, the interstitial space contained increased amount of collagen fibers (fig. 4).

\section{3- Bisphenol and indole group:}

By H\&E stain, the acini were lined by simple columnar epithelium with formation of subepithelial capillaries. The acini were surrounded by slightly thick fibromuscular stroma. The interstitial space contained scanty connective tissue and congested blood vessels (fig. 5a, 5b ). By Masson's Trichrome stain, The interstitial space contained scanty collagen fibers (fig. 6).

\section{Electron microscopy:}

\section{1- Control Group:}

The columnar cells lining the acinus had apical microvilli and contained basal nuclei with prominent nucleoli, normal mitochondria, Golgi complex, and plenty of rough endoplasmic reticulum. A basal cell was noted resting on the basement membrane (fig. 7a, 7b).

\section{2- Bisphenol group:}

The acinar cells had multiple levels of irregular, heterochromatic nuclei with different sizes and contain dark, irregular nucleoli. These signs indicated the hyperplasia. The acinar cell lacked the apical microvilli and contained vacuolated mitochondria, Golgi complex and rough endoplasmic reticulum. There were multiple 
layers of fibroblasts outside the basement membrane (fig. 8a, 8b).

\section{3- Bisphenol and indole group:}

The columnar cells lining the acinus contained rounded basal nuclei with prominent nucleoli. The chromatin material was condensed around the periphery of nuclei. The cytoplasm contained normal mitochondria, Golgi complex and rough endoplasmic reticulum. The luminal surface of the columnar cells had microvilli. A basal cell was noted resting on the basement membrane (fig. 9).

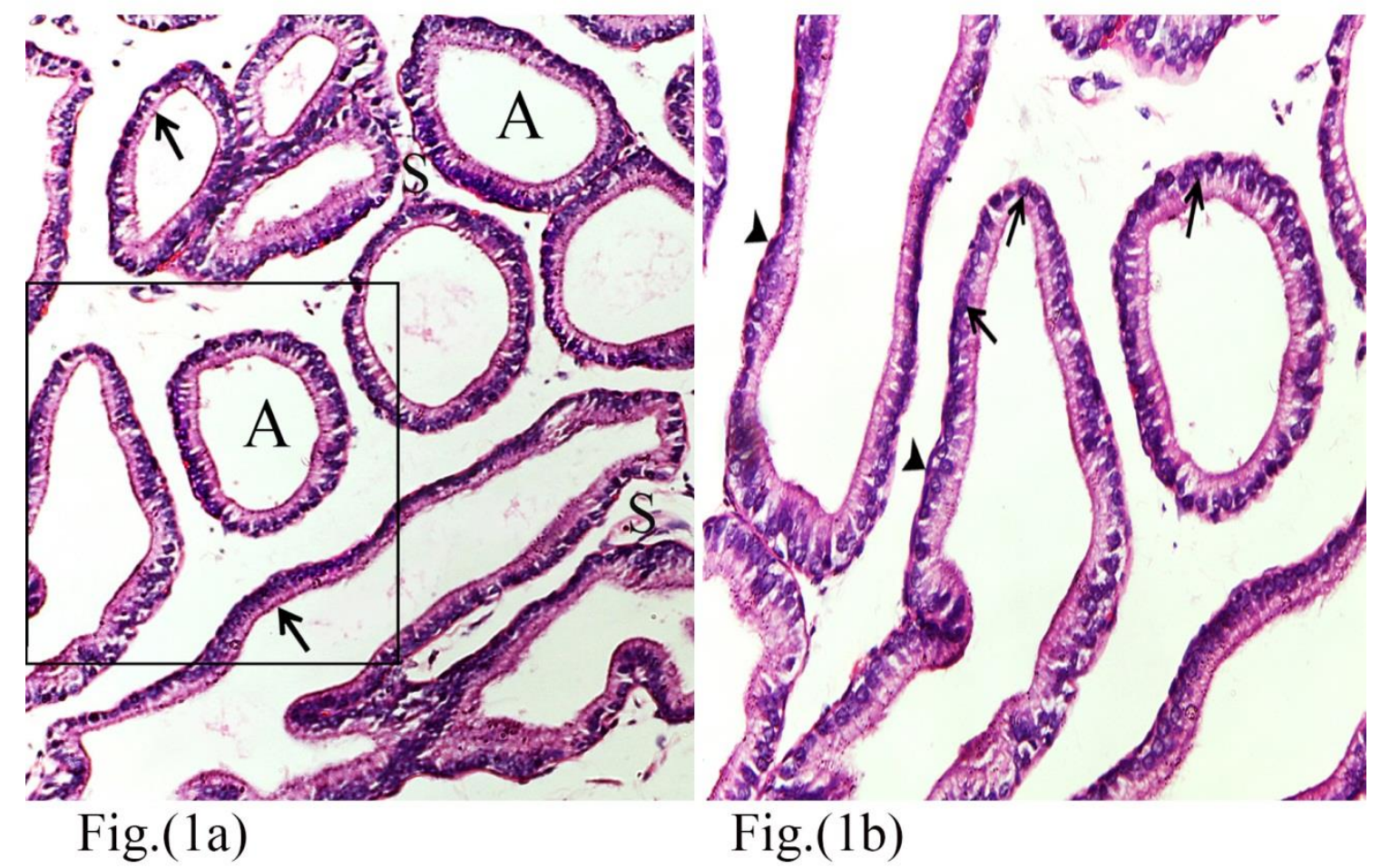

Fig. 1(a): A photomicrograph of a section of a prostate gland of a rat from (control group) aged 1 month old showing: Acini (A) are lined with simple columnar epithelium (arrows). The interstitial space contains scanty connective tissue ( $(\mathrm{H} \& \mathrm{E} \times 200)$

Fig. 1(b): A higher magnification of the previous section showing: The epithelial cells have basal dark rounded nuclei and supranuclear pale acidophilic cytoplasm ( arrows ). The acini are surrounded by a delicate layer of fibromuscular stroma (arrow heads) (H\&E x400) 


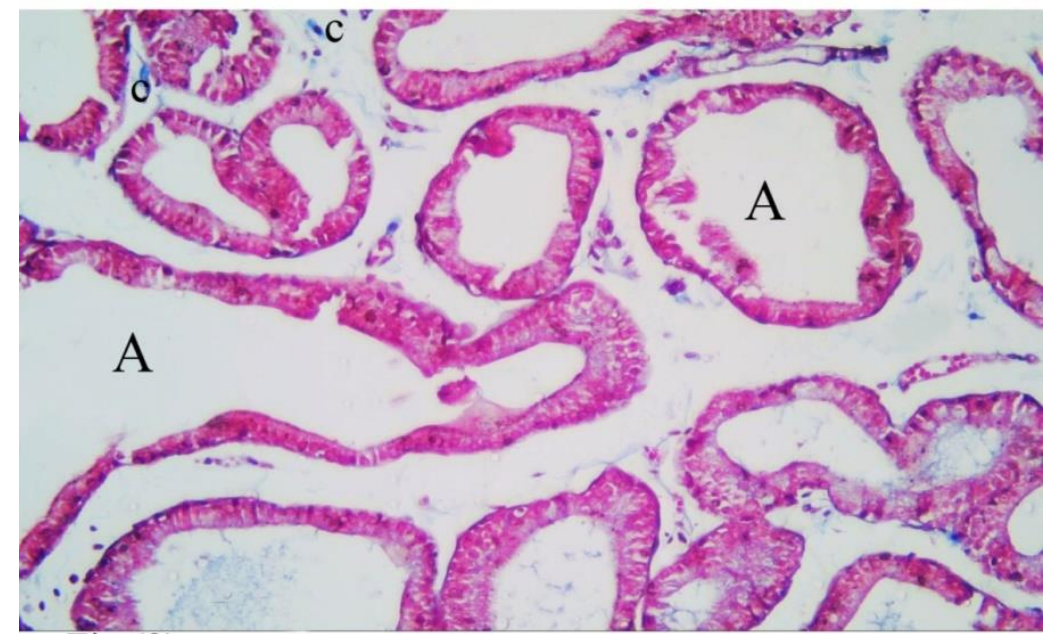

Fig.(2)

Fig. 2: A photomicrograph of a section of a prostate gland of a rat from (control group) aged 1 month old showing: The interstitial space in between the acini (A) contains scanty collagen fibers (C). (Masson's Trichrome x 200)

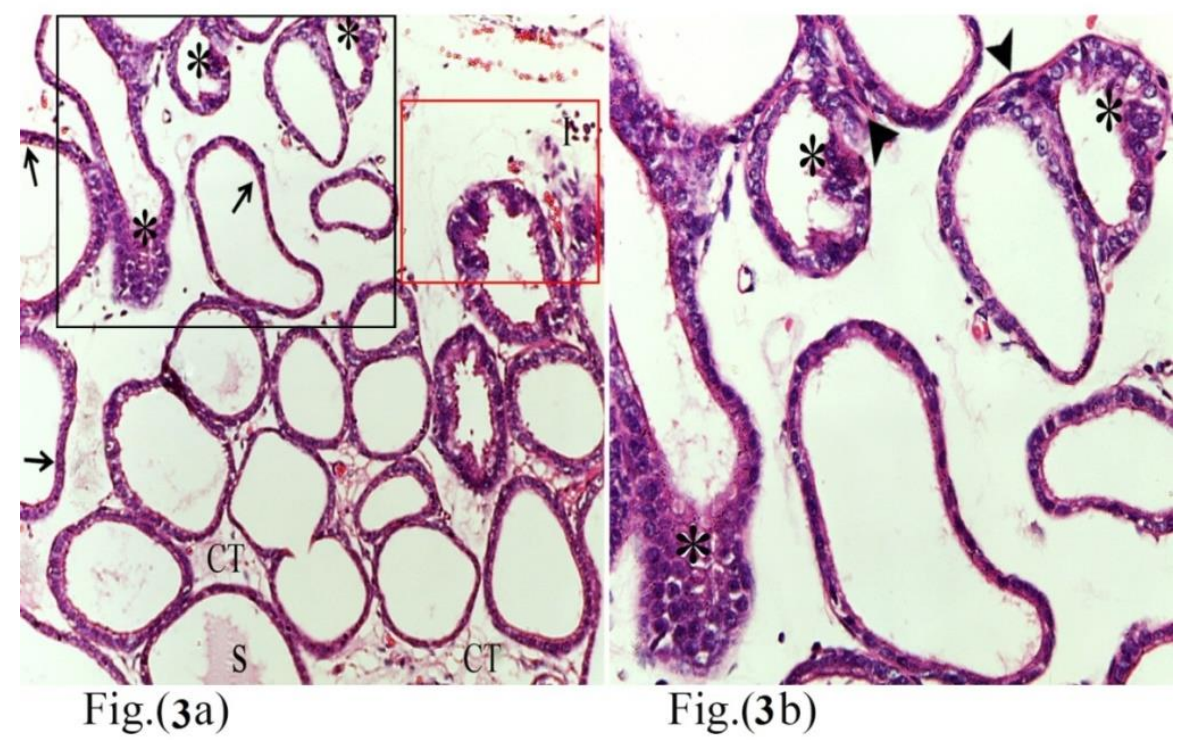

Fig. 3(a): A photomicrograph of a section of a prostate gland of a rat from (bisphenol group) aged 1 month old showing: Some acini are lined with simple columnar epithelium (arrows) but others have epithelial hyperplasia (star). Some acini contain acidophilic secretions (S). The interstitial space contains increased amount of connective tissue (CT) and inflammatory cells (I). (H\&E x200)

Fig. 3(b):A higher magnification of the previous section showing: Epithelial hyperplasia in some acini (star). There is slightly thick fibromuscular stroma around some acini (arrow heads) (H\&E x400) 


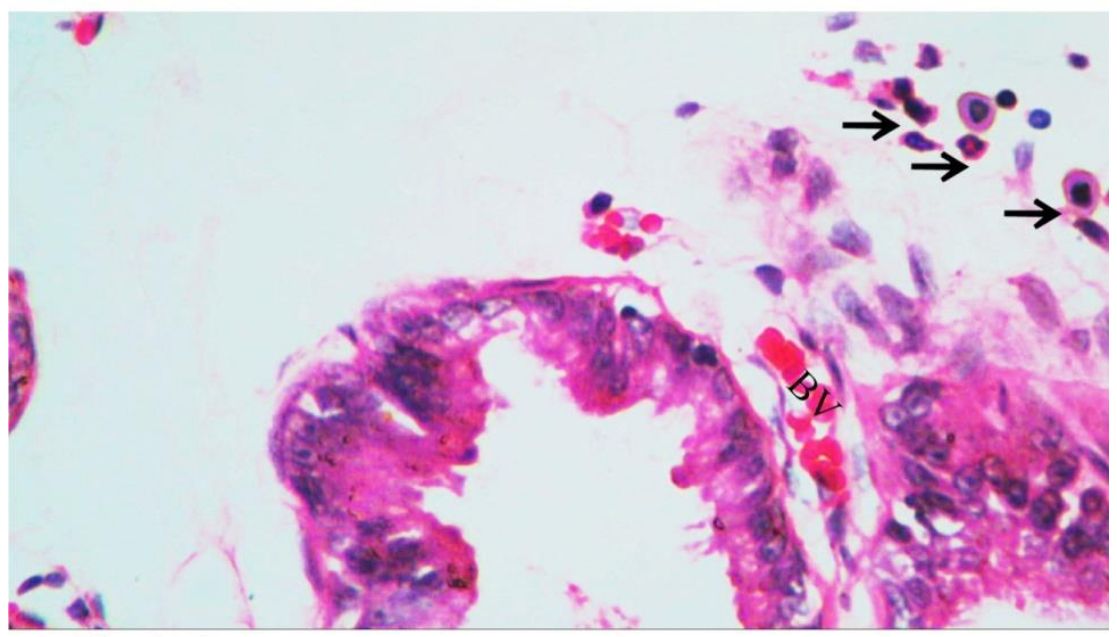

Fig.(3c)

Fig. 3(c): A higher magnification of fig. 3(a) showing: The interstitial space contains congested blood vessel (BV) and inflammatory cells (arrows). (H\&E x400)

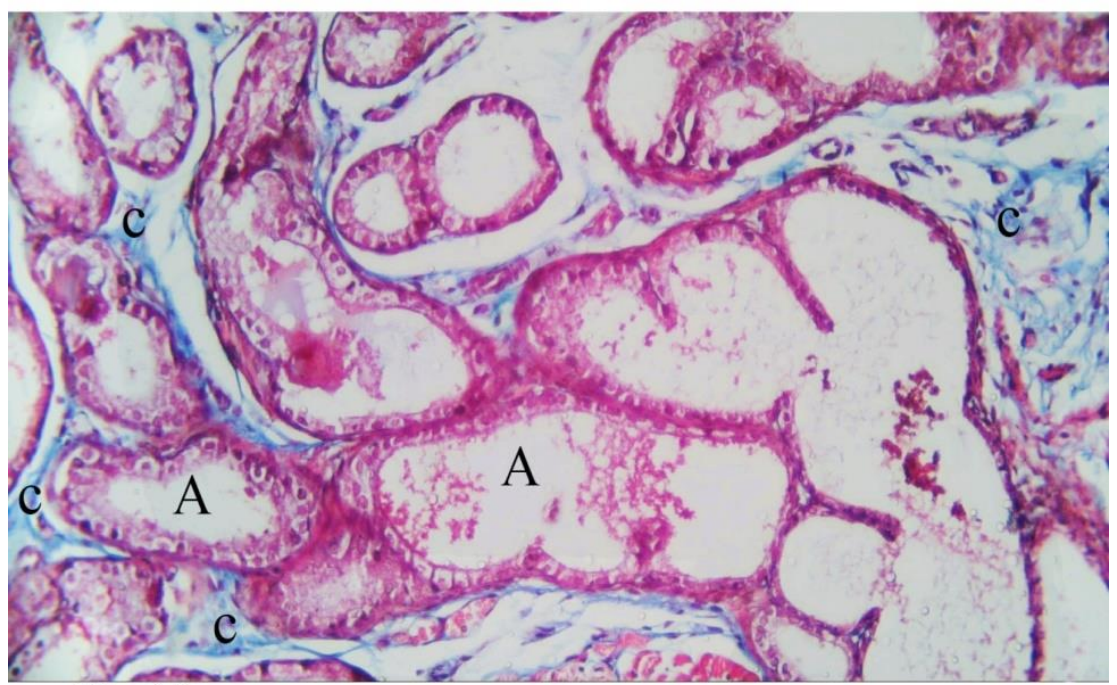

Fig.(4)

Fig. 4: A photomicrograph of a section of a prostate gland of a rat from (bisphenol group) aged 1 month old showing: The interstitial space in between the acini (A) contains increased amount of collagen fibers (C). (Masson's Trichrome x200) 


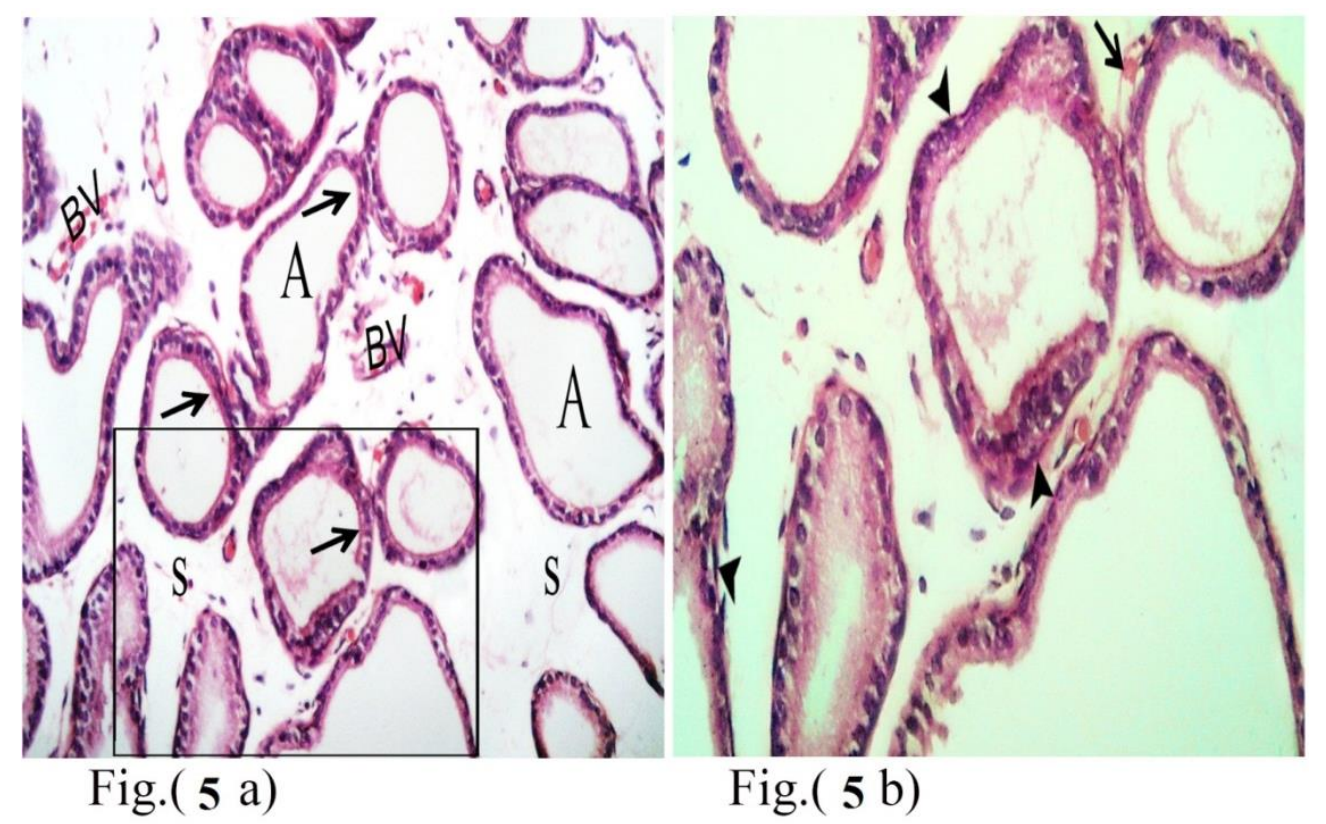

Fig. 5(a): A photomicrograph of a section of a prostate gland of a rat from (bisphenol and indole group) aged 1 month old showing: Acini (A) are lined by simple columnar epithelium (arrow) and the interstitial space contains scanty connective tissue (S) and congested blood vessels (BV). (H\&E x200)

Fig. 5(b): A higher magnification of the previous section showing: Slightly thick fibromuscular stroma around some acini (arrow heads) and formation of subepithelial capillaries (arrow). (H\&E x400)

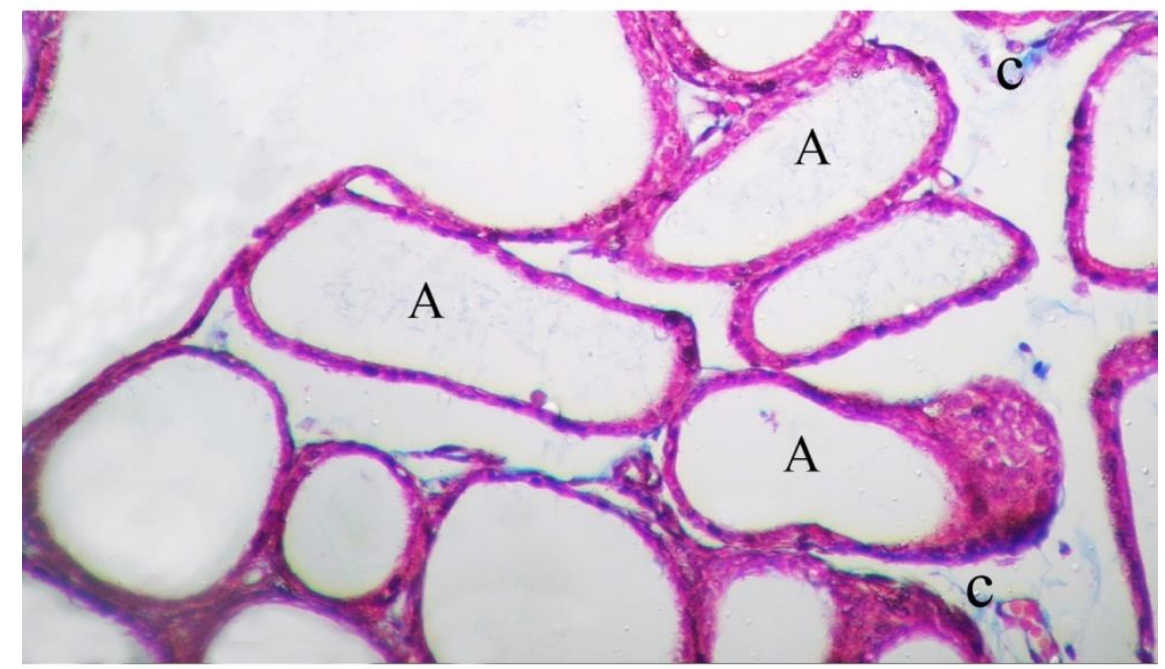

Fig.(6)

Fig. 6: A photomicrograph of a section of a prostate gland of a rat (bisphenol and indole group) aged 1 month old showing: The interstitial space in between the acini (A) contains scanty collagen fibers (C). (Masson's Trichrome x200) 


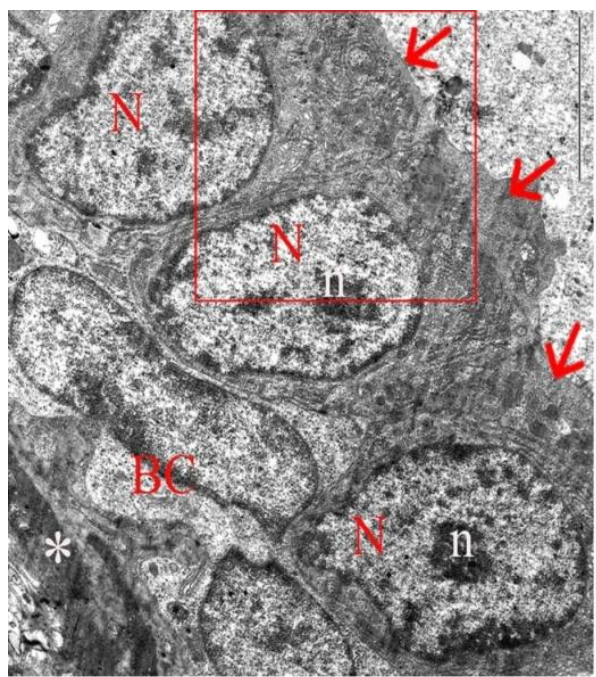

Fig.(7 a)

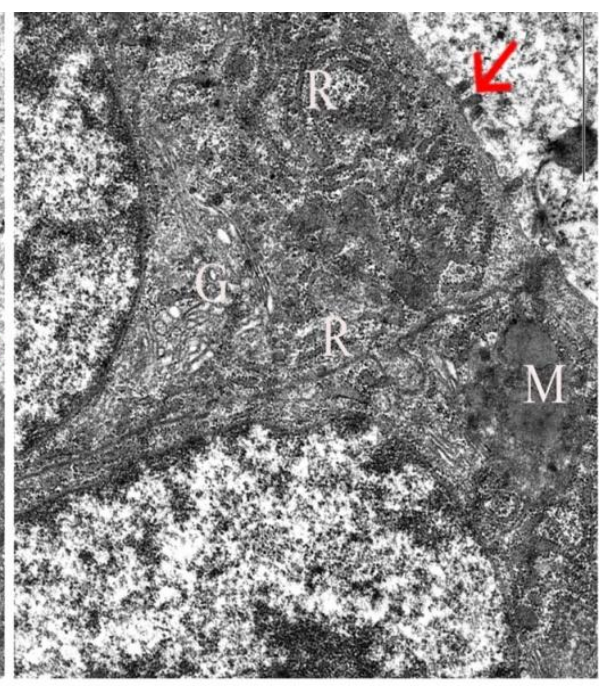

Fig.(7 b)

Fig. 7(a): An electron micrograph of a section of a prostate gland of a rat (control group) aged 1 month old showing: The columnar epithelium lining the acinus (arrows). The columnar cells contain basal nuclei $(\mathrm{N})$, with prominent nucleoli (n). Notice the basement membrane (star) with a basal cell (BC) resting on it. (E/M x2000)

Fig. 7(b): A higher magnification of the previous section showing: The columnar cells have apical microvilli (arrow) and contain normal mitochondria $(\mathrm{M})$, Golgi complex $(\mathrm{G})$ and plenty of rough endoplasmic reticulum $(\mathrm{R}) . \quad(\mathrm{E} / \mathrm{M} \times 5000)$

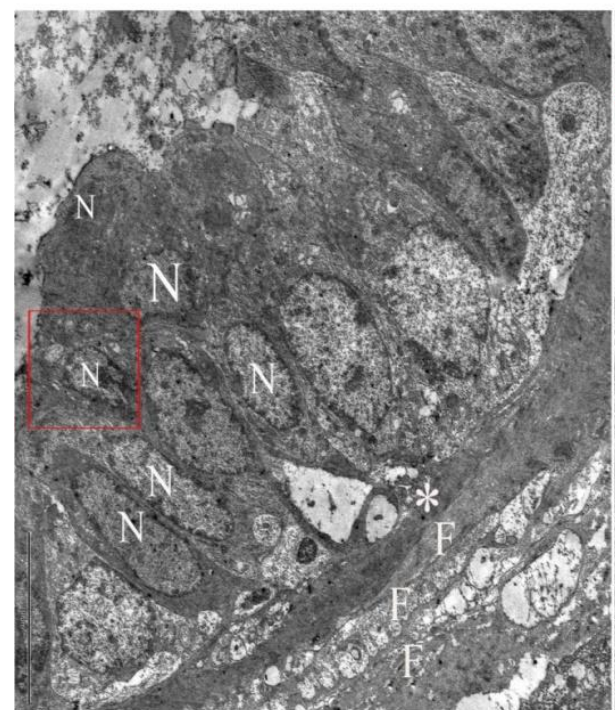

Fig.(8 a)

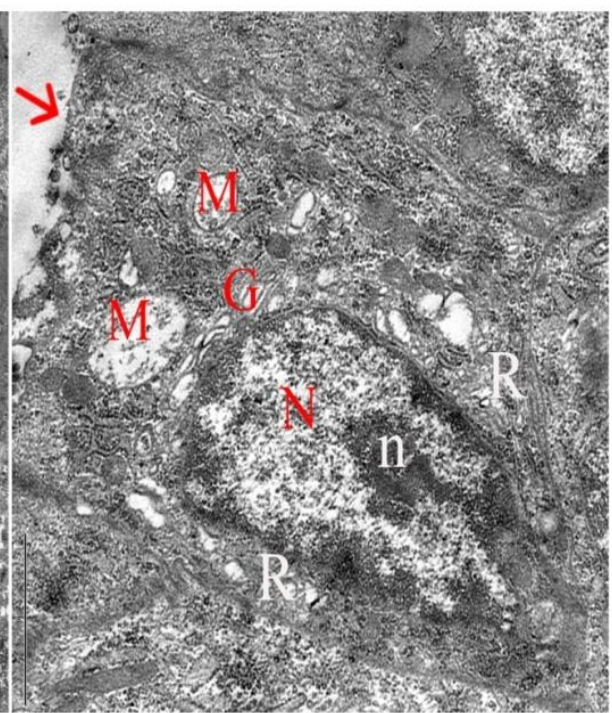

Fig. $(8$ b)

Fig. 8(a): An electron micrograph of a section of a prostate gland of a rat from (bisphenol group) aged 1 month old showing: The acinar cells have multiple levels of nuclei $(\mathrm{N})$. The nuclei have different sizes and irregular shapes. These signs indicate the hyperplasia. Notice the dark layer of basement membrane (star) and multiple layers of fibroblasts (F) outside it.(E/M x1000) 
Fig. 8(b): A higher magnification of the previous section showing: The acinar cell lacks the apical microvilli (arrow) and contains irregular, heterochromatic nucleus $(\mathrm{N})$ with dark, irregular nucleolus $(\mathrm{n})$. The mitochondria are vacuolated with loss of their cristae $(M)$. Notice Golgi complex $(G)$ and rough endoplasmic reticulum $(R)(E / M \times 5000)$

Fig.(9)

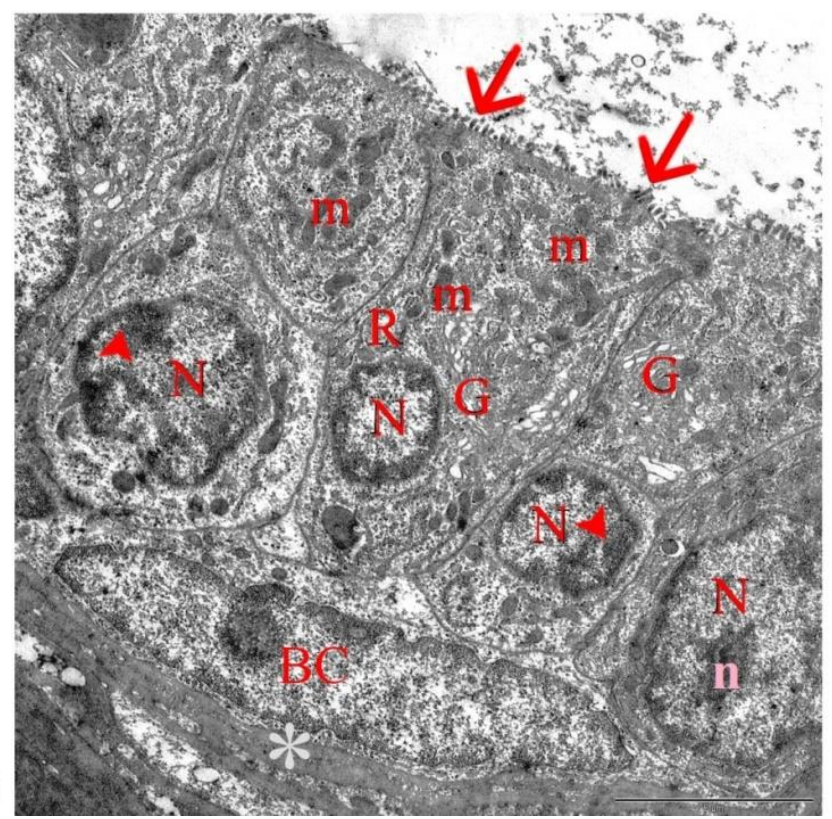

Fig. 9: An electron micrograph of a section of a prostate gland of a rat from (bisphenol and indole group) aged 1 month old showing: The columnar epithelium lining the acinus (arrows). The columnar cells contain rounded basal nuclei $(\mathrm{N})$, with prominent nucleolus (n). The chromatin material is condensed around the periphery of nuclei (arrow heads). The cytoplasm contains normal mitochondria (m), Golgi complex (G) and rough endoplasmic reticulum (R). The luminal surface of the columnar cells has microvilli (arrows). Notice the basement membrane (star) and the basal cell (BC) resting on it. $(\mathrm{E} / \mathrm{M} \times 2000)$

\section{B-Prostate gland of rats aged 3 months:}

\section{Light microscopy:}

\section{1- Control group:}

By $H \& E$ stain, the acini were lined with simple columnar epithelium with basal dark rounded nuclei and supranuclear pale acidophilic cytoplasm. The acini were surrounded by a delicate layer of fibromuscular stroma. The interstitial space contained scanty connective tissue (fig. 10a, 10b). By Masson's Trichrome stain, the interstitial space contained scanty collagen fibers (fig. 11).

\section{2- Bisphenol group:}

By H\&E stain, some acini had intraluminal papillary projections. Epithelial hyperplasia was seen in some acini and some epithelial cells showed vacuolated cytoplasm. The 
interstitial space contained congested blood vessels and increased amount of connective tissue (fig. 21a, 12b). By Masson's Trichrome stain, the interstitial space contained increased amount of collagen fibers (fig. 13).

\section{3- Bisphenol and indole group:}

By $H \& E$ stain, the acini were lined by simple columnar epithelium with basal dark rounded nuclei and supranuclear pale acidophilic cytoplasm. Some epithelial cells had cytoplasmic vacuolation. The fibromuscular layer around the acini was delicate. The interstitial space contained scanty connective tissue and congested blood vessels (fig. 14a, 14b). By Masson's Trichrome stain, the interstitial space contained scanty collagen fibers (fig. 15).

\section{Electron microscopy:}

\section{1- Control Group:}

The columnar cells lining the acinus has apical microvilli and contains basal nuclei, normal mitochondria, Golgi complex and rough endoplasmic reticulum (fig. 16a, 16b).

\section{2- Bisphenol group:}

The acinar cells had multiple levels of nuclei with different sizes and irregular in shape. Some cells have mitotic figures. These signs indicated the hyperplasia. The acinar cells had degenerated apical microvilli. The supranuclear cytoplasm contained lysosomes and dilated vacuolated mitochondria beside the other normal mitochondria, Golgi complex and rough endoplasmic reticulum (fig. 17a, 17b).

\section{3- Bisphenol and indole group:}

The columnar cells lining the acinus contained basal nuclei. The cytoplasm contained normal mitochondria, Golgi complex and rough endoplasmic reticulum. The luminal surface of the columnar cells had microvilli (fig. 18) 


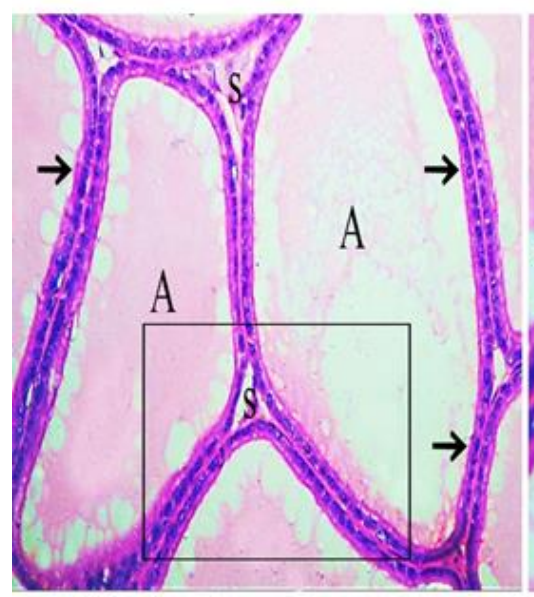

Fig.(10 a)

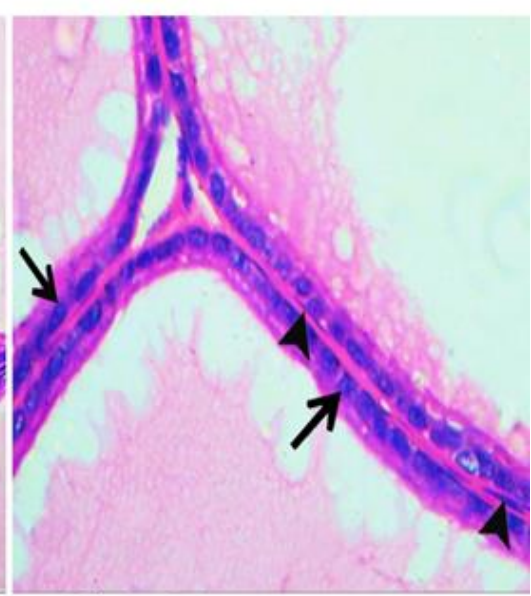

Fig(10b)

Fig. 10(a): A photomicrograph of a section of a prostate gland of a rat from (control group) aged 3 months old showing: Acini (A) are lined with simple columnar epithelium (arrows). The interstitial space contains scanty connective tissue (S). $(\mathrm{H} \& \mathrm{E} \times 200)$

Fig. 10(b): A higher magnification of the previous section showing: The epithelial cells have basal dark rounded nuclei and supranuclear pale acidophilic cytoplasm (arrows). The acini are surrounded by a delicate layer of fibromuscular stroma (arrow heads). (H\&E x400)

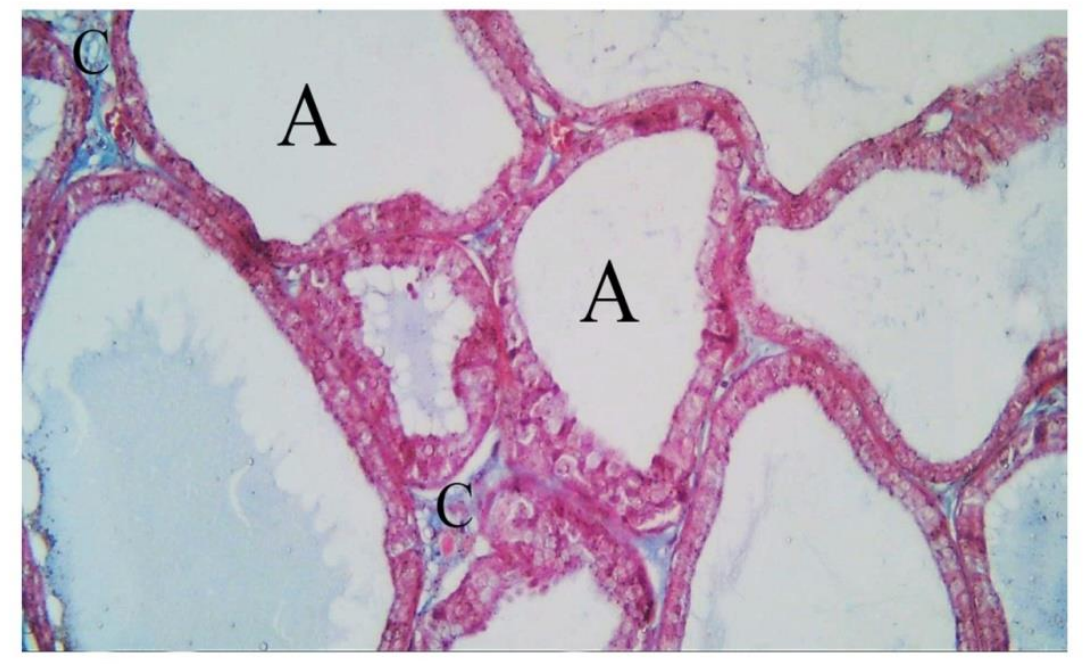

Fig.(11)

Fig. 11: A photomicrograph of a section of a prostate gland of a rat from(control group) aged 3 months old showing: The interstitial space in between the acini (A) contains scanty collagen fibers (C). (Masson's Trichrome $\mathrm{x} 200$ ) 


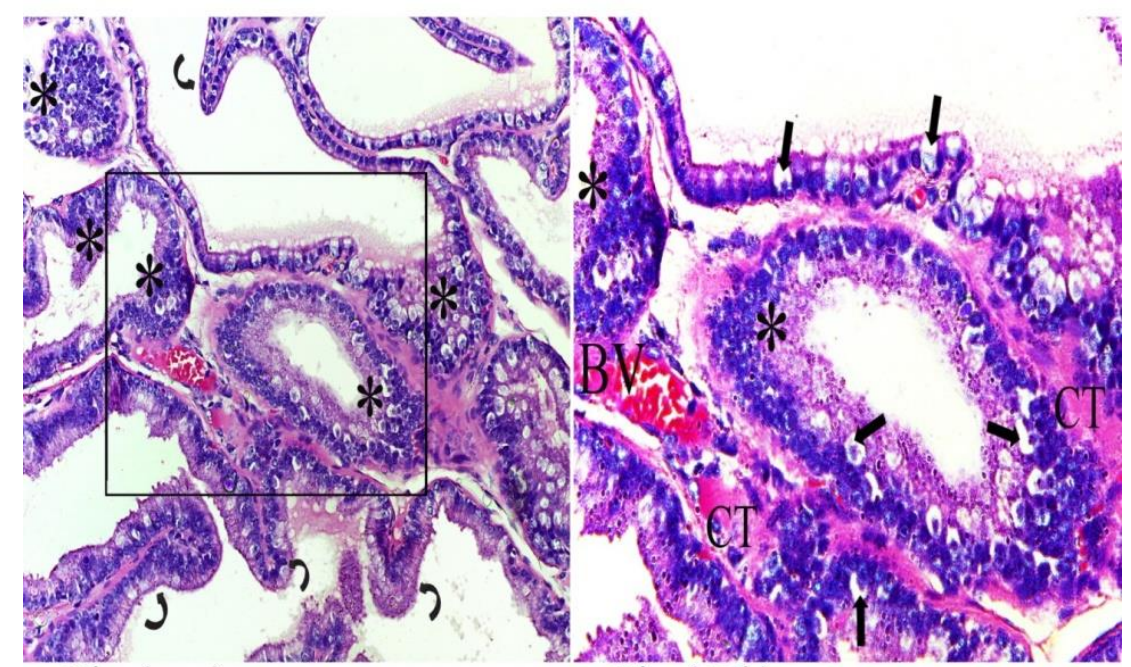

Fig.(12a)

Fig.(12b)

Fig. 12(a): A photomicrograph of a section of a prostate gland of a rat from (bisphenol group) aged 3 month old showing: Some acini have multiple intraluminal papillary projections (curved arrows). Epithelial hyperplasia is seen in some acini (star). (H\&E x200)

Fig. 12(b): A higher magnification of the previous section showing: Epithelial hyperplasia is seen in some acini( star ). Some epithelial cells show vacuolated cytoplasm (arrows). The interstitial space contains congested blood vessels (BV) and increased amount of connective tissue (CT). (H\&E x400)

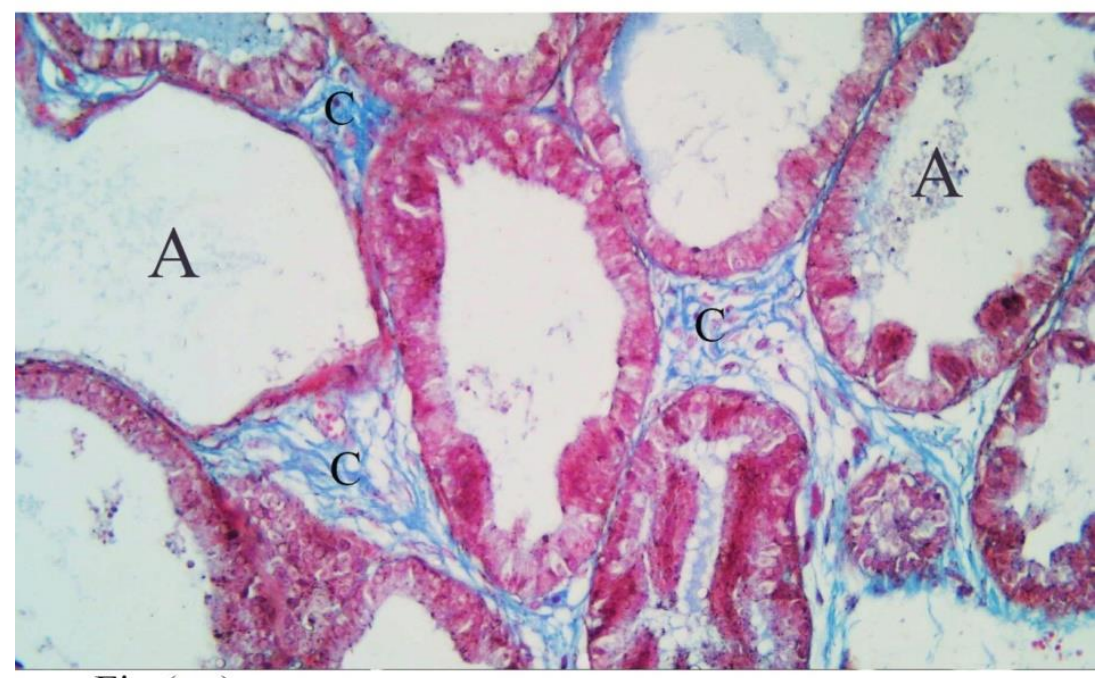

Fig.(13)

Fig. 13: A photomicrograph of a section of a prostate gland of a rat from (bisphenol group) aged 3 months old showing: The interstitial space in between the acini (A) contains increased amount of collagen fibers (Masson's Trichrome x200) 


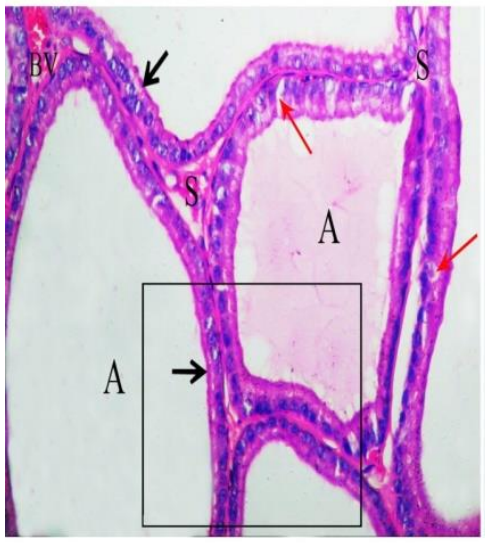

Fig.(14a)

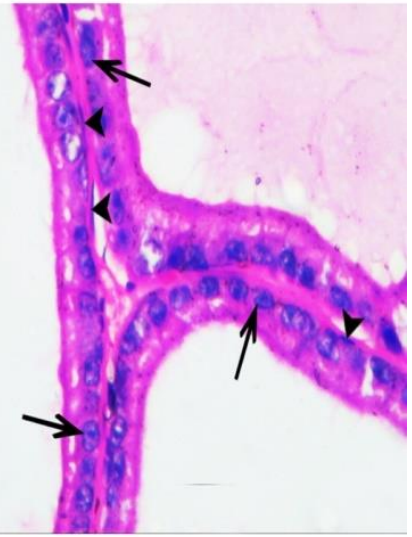

Fig.(14 b)

Fig. 14(a): A photomicrograph of a section of a prostate gland of a rat from (bisphenol and indole group) aged 3 months old showing: The acini (A) are lined by simple columnar epithelium (black arrows). Some epithelial cells have cytoplasmic vacuolation (red arrows). The interstitial space contains scanty connective tissue (S) and congested blood vessel (BV). (H\&E x200)

Fig. 14(b): A higher magnification of the previous section showing: The epithelial cells have basal dark rounded nuclei and supranuclear pale acidophilic cytoplasm (arrows). The fibromuscular layer around the acini is delicate (arrow heads). $(\mathrm{H} \& \mathrm{E} x 400)$

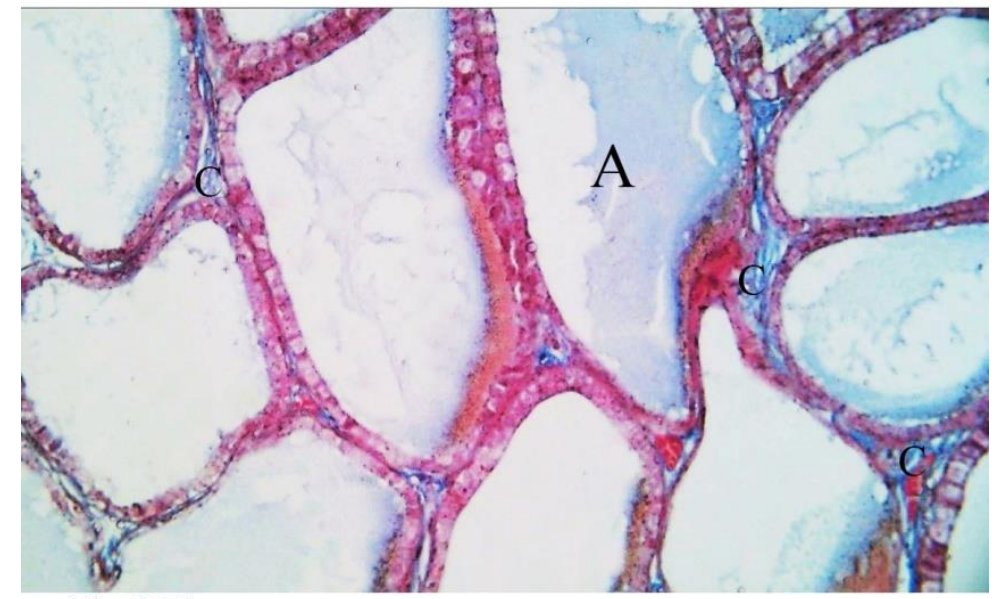

Fig.(15)

Fig. 15: A photomicrograph of a section of a prostate gland of a rat from (bisphenol and indole group) aged 3 months old showing: The interstitial space in between the acini (A) contains scanty collagen fibers (C). (Masson's Trichrome x200) 


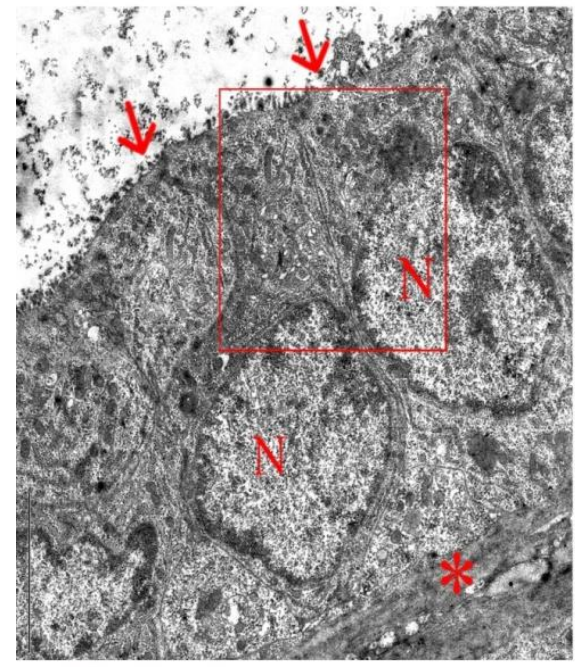

Fig.(16a)

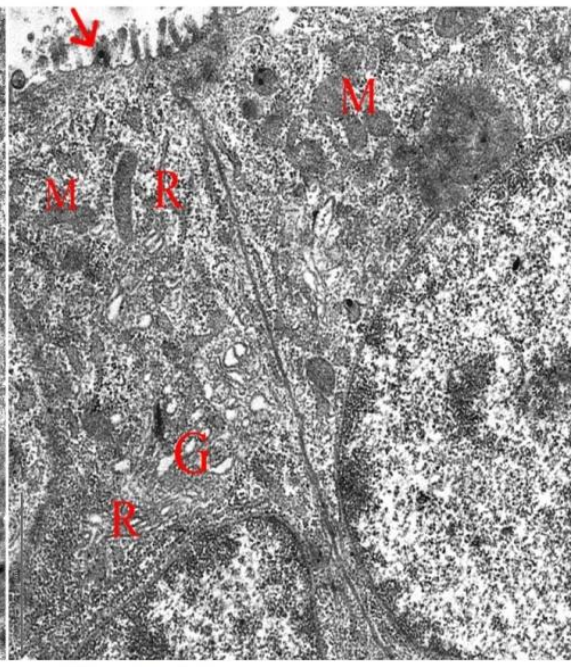

Fig.(16b)

Fig. 16 (a): An electron micrograph of a section of a prostate gland of a rat from (control group) aged 3 months old showing: The columnar epithelium lining the acinus (arrows) .The columnar cells contain basal nuclei (N). Notice the basement membrane (star).(E/M x2000)

Fig. 16 (b): A higher magnification of the previous section showing: The columnar cells have apical microvilli (arrow) and contain normal mitochondria $(\mathrm{M})$, Golgi complex $(\mathrm{G})$ and rough endoplasmic reticulum (R). (E/M x5000)

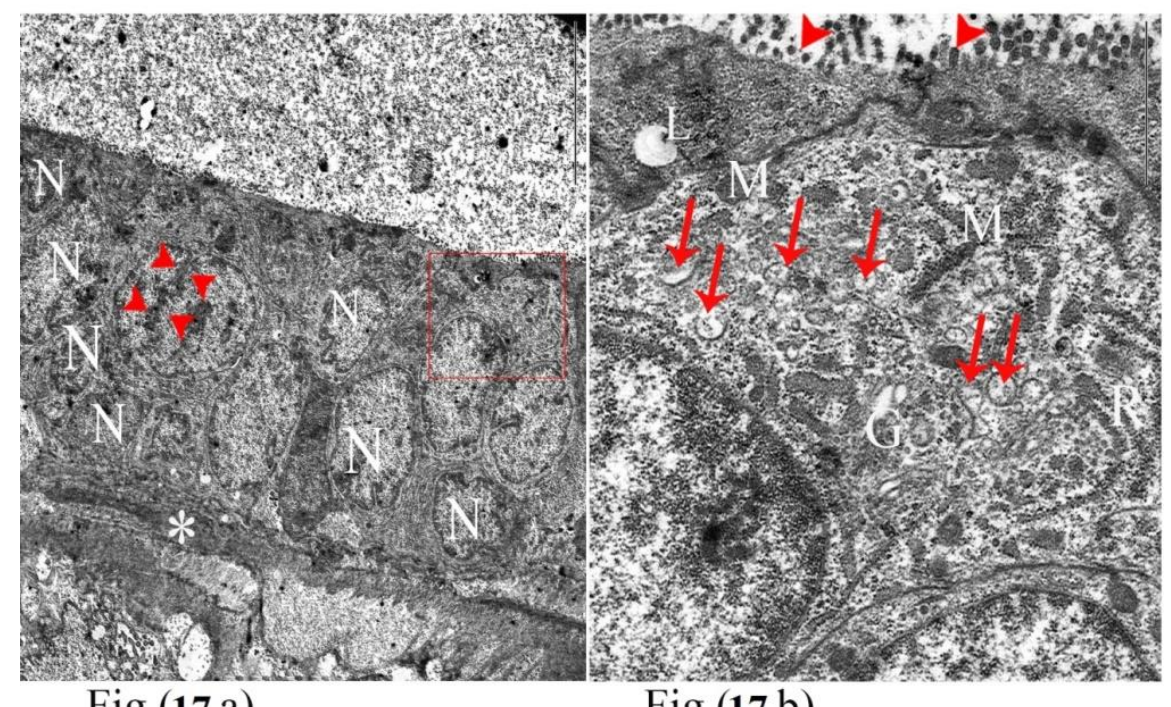

Fig.(17 a)

Fig.(17 b)

Fig. 17(a): An electron micrograph of a section of a prostate gland of a rat from (bisphenol group) aged 3 months old showing: The acinar cells have multiple levels of nuclei $(\mathrm{N})$. The nuclei have different sizes and irregular in shape. These signs indicate the hyperplasia. Notice the dividing epithelial cell (arrow heads) and the basement membrane (star).(E/M $\mathrm{x} 1000)$ 
Fig. 17(b): A higher magnification of the previous section showing: The luminal surface of the epithelial cells has degenerated microvilli (arrow heads). The supranuclear cytoplasm contains dilated and vacuolated mitochondria (arrows) and lysosomes (L). Other mitochondria are intact (M). Notice normal Golgi complex (G) and rough endoplasmic reticulum $(\mathrm{R}) . \quad(\mathrm{E} / \mathrm{M} \times 5000)$

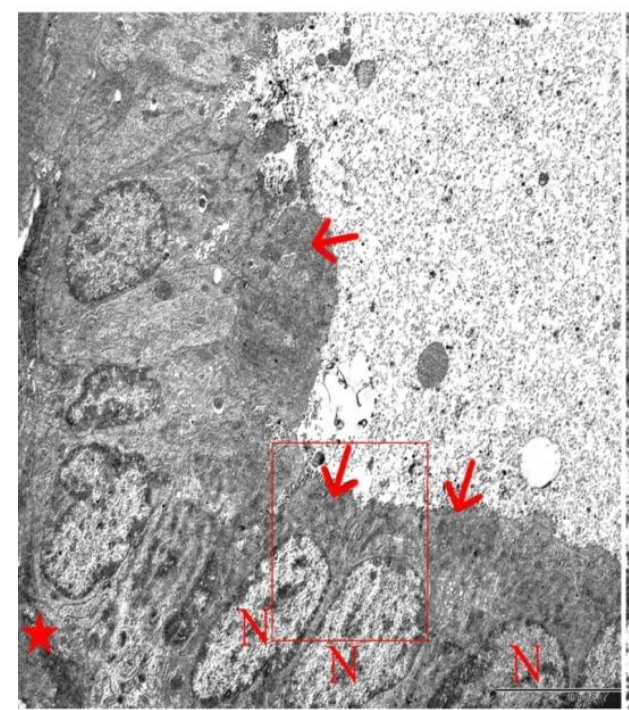

Fig.(18a)

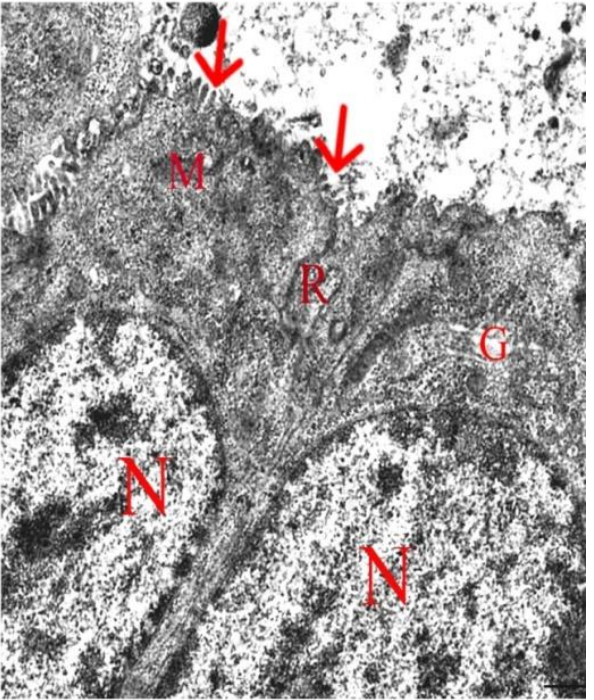

Fig.(18b)

Fig. 18(a): An electron micrograph of a section of a prostate gland of a rat from (bisphenol and indole group) aged 3 months old showing: The columnar epithelium lining the acinus (arrows). The columnar cells contain basal nuclei $(\mathrm{N})$. Notice the basement membrane (star). (E/M x1000)

Fig. 18(b): A higher magnification of the previous section showing: The cells contain basal nuclei(N). The luminal surface of the columnar cells has microvilli (arrows). The cytoplasm contains normal mitochondria (M), Golgi complex (G) and rough endoplasmic reticulum (R). (E/M x5000)

\section{Discussion:}

The present study was carried out to show the effect of prenatal exposure to $25 \mathrm{mg}$ bisphenol $\mathrm{A} / \mathrm{kg} \mathrm{BW}$ on rat prostate gland at ages 1 and 3 months. This study also investigated the protective effect of gestational exposure to I3C on the harmful effects of BPA on rat prostate gland.In the present study, histological examination of prostates of BPA treated group at both ages revealed epithelial hyperplasia and in addition at 3 months showed increased intraluminal papillary projections. These findings run in accordance with Brandt et al. [13] and Hassan et al. [15]. They detected epithelial hyperplasia and papillary projections in prostates from rat's pre and postnatally exposed to BPA. 
Also these findings are in agreement with Huang et al. [16] who revealed glandular prostatic hyperplasia with an increase in the degree of papillary in folding in adult rat prostates treated by BPA for 30 days.

This prostatic hyperplasia and intraluminal papillary projections were explained by

Huang et al. [17], who reported that the prostate gland is sensitive to estrogen, and that exposure to synthetic estrogens alters prostate development and differentiation. The hyperplasia of prostatic acini results from increasing the proliferation of basal epithelial cells [18].

In the present study, the thick fibromuscular stroma around the prostatic acini of BPA treated group aged 1 month is in agreement with Ramos et al. [19]. They detected an increase in stroma of prostate in BPA-treated animals and demonstrated presence of thicker layer of fibroblasts by using vimentin and smooth muscle actin markers. They suggested that could be the result of either a modified proliferation: apoptosis ratio in early stages of development or altered differentiation of periacinar mesenchymal cells.

In our study, the interstitial space of prostates of BPA treated groups at both ages of the experiment, showed congested blood vessels. This finding runs in accordance with other study.[20]. They found congestion of the interstitial space of prostates from rats aged 1.5 months treated with $100 \mathrm{mg}$ g BPA / kg bw for 15 days. Also, congested blood vessels were detected in the interstitial space of prostates from adult rats treated with $10 \mathrm{mg}$ BPA / kg BW for 14 days. [21]

The mechanism of the interstitial blood vessels dilatation is explained by the fact that the increase in the ratio of oxygen need to the oxygen supply causes an increased adenosine production rate which lead to dilatation of the vessels and increased blood flow in order to restore the oxygen ratio to the normal level.

\section{[22]}

The present study detected the presence of inflammatory cells in the interstitial space of prostates from BPA treated rats, at age of 1 month. This finding is partially in agreement with others who detected multifocal inflammatory infiltrate, predominantly comprised mononuclear cells which is a characteristic of chronic inflammation, in Sprague Dawley rat ventral prostate at 6 months of age after prenatal exposure to 25 $\mathrm{mg} / \mathrm{kg}$ bw/day of BPA. But in contrast to our study he did not found the same finding in rats at age of 21 days. [23],

The interstitial inflammation detected by the present study also runs in accordance with a 
research which showed that exposure to endocrine disruptors during pregnancy can increase incidence of inflammatory foci. [24]. Also it was revealed that acute prostatitis with severe inflammatory cells infiltration, inside and around the prostatic acini, in adult rat was treated by BPA. [25]

This study showed vacuolated cytoplasm in epithelial cells of BPA treated groups at ages of 3 months. This finding is in agreement with the histological findings reported before, as rupture and vacuolation in epithelium of the secretory units of prostates from rats, aged 1.5 months, treated by $50 \mathrm{mg} / \mathrm{kg}$ bw/day of BPA for 15 days. [20]

In the present study, at both ages, the Masson's Trichrome stained sections showed increased amount of collagen fibers in the interstitial space of BPA treated prostates. These data are in agreement with what was reported as increased density of collagen fibers that appeared as compact bundles around the prostatic acini at ages of 21 and 180 days from rats prenatally treated by BPA at doses of 25 $\mathrm{mg} / \mathrm{kg}$ bw/day [13]. Also it was reported that great amount of the collagen fibers around the acini and around the dilated congested blood vessels in Masson's Trichrome stained prostatic sections from adult rats treated by
BPA at dose of $25 \mathrm{mg} / \mathrm{kg}$ bw/day for 30 days. [25]

In the present study, at both ages, the ultrastructural examination of prostates from BPA treated group, revealed epithelial hyperplasia with multiple levels of heterochromatic nuclei. The nuclei were of different sizes and irregular shapes. These data are like those reported before that prenatal exposure to low doses of BPA resulted in appearance of hyperplastic lesions with nuclei of different sizes and shapes. [26]. This was also supported by the study carried out in the same year [27], in which Sprague-Dawley rats were treated with environmentally relevant dose of BPA at 1, 3 and 5 days after birth. They found that BPA increased the susceptibility of prostate gland to hyperplastic lesions with nuclei of different sizes and shapes.

These findings are also in concomitant with the study performed before where the effect of chronic administration of estradiol on prostate of guinea pigs. They observed in treated group areas of epithelial stratification with nuclei of various forms, sizes and heights as well as irregular chromatin distribution patterns, was examined [28].

In our work, the prostatic epithelium of BPA treated groups at both ages showed vacuolated 
mitochondria and loss of microvilli from the luminal surface of the cells. These findings are in accordance with others who observed the vacuolated mitochondria and loss of cellular activity in prostates of rats, aged 1.5 months and were treated by $100 \mathrm{mg} / \mathrm{kg}$ bw/day of BPA for 15 days. They also reported dilated rough endoplasmic reticulum and loss of microvilli in seminal vesicles of the same rats [20].

In the present study, the prostates from bisphenol and indole treated groups at both ages, showed nearly healthy simple columnar epithelium with basal regular nuclei and intact organelles. The interstitial space showed normal amounts of collagen fibers. These data run in accordance with a previous study where it was observed that stroma that appeared was less dense in cells and fibers and decreased incidence of multifocal inflammation, epithelial hyperplasia and papillary folds in rats treated prenatally by $\mathrm{BPA}$ and $\mathrm{I} 3 \mathrm{C}$ than the groups treated only by BPA [13].

More studies [11and 29] observed a significant reduction in the histological progression of prostate tumors in transgenic adenocarcinoma of the mouse prostate in mice that received $\mathrm{I} 3 \mathrm{C}$.

In addition, it was demonstrated that I3C could increase the antioxidant activity of nuclear factor-erythroid 2-related factor in prostate tumor cells. As a result, better protection against oxidative stress and its induced tissue damage, and reduced inflammatory effect due to BPA were observed [11].

\section{Conclusion:}

Prenatal exposure to BPA has a harmful effect on prostate development and growth. Maternal I3C feeding during pregnancy has a great protective effect and can reduce the harmful effects of gestational BPA imprinting on the prostate.

\section{References:}

1- Rubin B.S. (2011): Bisphenol A: an endocrine disruptor with widespread exposure and multiple effects. J Steroid Biochem Mol Biol; 127: $27-34$.

2- Vogel S.A. (2009): The politics of plastics: the making and unmaking of bisphenolasafety. Am J Public Health 99, no. S3:559-66

3- Fernandez M.F., Arrebola J.P., Taoufiki J., Nafalón A., Ballesteros O., Pulgar R., et al. (2007): Bisphenol-A and chlorinated derivatives in adipose tissue of women. Reprod Toxicol 24:259-264

4- Zalko D., Jacques C., Duplan H., Bruel S. and Perdu E. (2011):Viable skin efficiently absorbs and metabolizes bisphenol A. Chemosphere $82: 424-430$

5- Vandenberg L.N., Colborn T., Hayes T.B., Heindel. J.J., Jacobs D.R Jr, Lee D.H., et 
al.(2013): Regulatory decisions on endocrine disrupting chemicals should be based on the principles of endocrinology. Reprod Toxicol 38:1-15.

6- Takahashi O. and Oishi S. (2000): Disposition of orally administered2,2-bis(4hydroxyphenyl)propane (bisphenol A) in pregnantrats and the placental transfer to fetuses. Environ Health Perspect 108:931-935.

7- Zalko D., Soto A.M., Dolo L., Dorio C., Rathahao E., Debrauwer L. et al. (2003): Biotransformations of bisphenol $\mathrm{A}$ in $\mathrm{a}$ mammalian model: answers and new questions raised by low dose metabolic fate studies in pregnant CD1 mice. Environ Health Perspect 111: $309-319$.

8- Munoz-de-Tore M., Markey C., Wadia P.R., Luque E. H., Rubin B. S., Sonnenschein C. et al. (2005): Perinatal exposure to bisphenol A alters peripubertal mammary gland development in mice, Endocrinology 146: 4138 - 4147.

9- Ramos J. G., Varayoud J., Kass L., Rodríguez H., Costabel L., Toro M. M. and Luque E. H. (2003): Bisphenol A induces both transient and permanent histofunctional alterations of the hypothalamic-pituitary-gonadal axis in prenatally exposed male rats. Endocrinol, 144(7): 3206-3215.

10- Tang W.Y., Morey L. M., Cheung Y. Y., Birch L., Prins G. S. and Ho S. M. (2012): Neonatal Exposure to Estradiol / Bisphenol A alters promoter methylation and expression of Nsbp1and Hpcal1 genes and transcriptional programs of Dnmt3a/b and Mbd2/4 in the rat prostate gland throughout life. Endocrinology; 153: 42-55.

11- Wu T.Y., Saw C. L., Khor T. O., Pung D., Boyanapalli S.S.S. and Kong A.T. (2011): In vivo pharmacodynamics of indole-3-carbinol in the inhibition of prostate cancer in transgenic adenocarcinoma of mouse prostate (TRAMP) mice: involvement of Nrf2 and cell cycle/apoptosis signaling pathways. Mol Carcinog ;51:761-70

12- Wang T.T., Milner M. J., Milner J. A., and Kim Y. S. (2006): Estrogen receptor alpha as a target for indole-3-carbinol. J Nutr Biochem ;17:65964

13- Brandt J.Z., Silveira L.T.R., Grassi T.F., Anselmo-Franci J.A., Fávaro W.J., Felisbino S.L., Barbisan L.F. and Scarano W.R. (2014): Indole-3-carbinol attenuates the deleterious gestational effects of bisphenol A exposure on the prostate gland of male F1 rats. Reprod. Toxicol. 43, 56-66.

14- Bancroft J. D., Layton C. and Suvarna S.K. (2018): The hematoxylins and eosin, Connective and other mesenchymal tissues with their stains, Transmission electron microscopy. Bancroft's Theory and practice of histological techniques. 8th ed., Churchill Livingstone of Elsevier, Philadelphia Ch. 10, P. 126-138, Ch.12, p. 153175 and Ch. 21, p. 434-475.

15- Hassan A., Ismail A. and Khudir A. (2013): Effects of Pre-and Postnatal Exposure to Bisphenol- A on the Reproductive Efficacy in Male Albino Rats. Journal of Kerbala University. 11(3): 158-172. 
16- Huang D. Y., Zheng C. C., Pan Q., Wu S. S., Su X., Li L., Wu J. H. and Sun Z. Y. (2018): Oral exposure of low-dose bisphenol A promotes proliferation of dorsolateral prostate and induces epithelial-mesenchymal transition in aged rats. Scientific reports, 8:490

17- Huang L., Pu Y., Alam S., Birch L., Prins G.S., (2004): Estrogenic regulation of signaling pathways and home-obox genes during rat prostate development. J Androl, 25: 330-337

18- Timms B., Howdeshell K., Barton L. et al. (2005): Estrogenic chemicals in plastic and oral contraceptives disrupt development of the fetal mouse prostate and urethra. Proc. Natl. Acad. Sci. 102:7014-7019.

19- Ramos J. G., Varayoud J., Sonnenschein C. Soto A. M., Toro M. M. and Luque E. H. (2001): Prenatal exposure to low doses of bisphenol A alters the periductalstroma and glandular cell function in the rat ventral prostate. Biol. Reprod., 65: 1271-1277

20- Hasanluyi E. A., Khojasteh S. M. B. and Nejhad D. M. ( 2016): Investigation of the Effects of Bisphenol A on the Histology and Ultrastructure of Prostate and Seminal Vesicle Glands in Rats: thrita 5 (4)e38611

21- Ola-Davies O. E., Olukole S. G. and Lanipekun D. O. (2018): Protective Effect of Gallic Acid against Bisphenol A-Induced Morphological Alterations of the Prostate Gland of Wistar Rats. The Pharmaceutical and Chemical Journal, 5(2):34-39

22- Kathryn S. and McCance K. (2008):The circulation sys-tem. Understanding pathophysiology text book. Mos-by/Elsevier, Oxford ; 22: pp 567-585

23- Bernardo B.D., Brandt J.Z., Grassi T.F., Silveira L.T., Scarano W.R. and BarbisanL.F. (2015): Genistein reduces the noxious effects of in utero bisphenol A exposure on the rat prostate gland at weaning and in adulthood. Food Chem Toxicol84, 64-73.

24- Scarano W.R., Toledo F.C., Guerra M.T., Campos S.G.P., Júnior L.A.J., Felisbino S.L. et al. (2009): Long-term effects of developmental exposure to di-n-butyl-phthalate (DBP)on rat prostate: proliferative and inflammatory disorders and a possible role of androgens. Toxicology ; 262:215-23.

25- Tolba A. M. and Mandour D. A. (2018): Histological effects of bisphenol-A on the reproductive organs of the adult male albino rat. Eur. J. Anat. 22 (2): 89-102 .

26- Ho S. M., Tang W. Y., Frausto J. B. and Prins G. S. (2006): Developmental exposure to estradiol and bisphenol A increases susceptibility to prostate carcinogenesis and epigenetically regulates phosphodiesterase type 4 variant 4. Cancer Res., 66: 5624-5632.

27- Tang W. Y., Prins G. S., Belmonte J. and Ho S. M. ( 2006): Neonatal exposure to estradiols or bisphenol A epigenetically alters phosphodiesterase type IV variant 4 (PDE4D4) and increases susceptibility to adult-induced prostate carcinogenesis. Carcinogenesis 5: Environmental and Endogenous Carcinogens. Proc. Amer. Assoc. Cancer Res., 47: 334-350. 
28- Scarano W. R., Cordeiro R. S., Góes R. M. and Taboga S. R. (2004): Intraepithelial alterations in the guinea pig lateral prostate at different ages after estradiol treatment. J. Submicrosc. Cytol. Pathol., 36(2): 141-148
29- Cho H.J., Park S.Y., Kim E.J., Kim J.K. and Park J.H. (2011): 3,3/-Diindolylmethane inhibits prostate cancer development in the transgenic adenocarcinoma mouse prostate model.Mol Carcinog;50:100-12.

To cite this article: Saadia A. Shalaby, Essam M. Eid, Omar A. Allam, Naglaa A. Sarg, Maged A. Behery Protective Effect of Indole 3 Carbinol on Toxicity of Prenatal Exposure of Bisphenol A on Adult Rat Prostate" A Light and Electron Microscopic Study". BMFJ 2021; 38(2): 590-612. DOI: $10.21608 / \mathrm{bmfj} .2021 .16304 .1049$ 